\title{
Telejornais: quem dá o tom?
}

Elizabeth Bastos Duarte, com a colaboração de Vanessa Curvello

\section{Resumo}

0 presente trabalho propõe-se, dando

continuidade às investigações desenvolvidas sobre o processo de tonalização dos produtos televisuais, a examinar com atenção o papel desempenhado em determinados programas de televisão pelo ator discursivo condutor do programa. Apresentadores, animadores, âncoras, entrevistadores, muitas vezes, concentram em si, além da tarefa de condução da própria emissão,

a função de mediação entre a instância de enunciação e os enunciatários do texto televisual, sendo responsáveis pela proposição, modulação, gradação e manutenção do tom da emissão televisual. Seria esse o caso dos apresentadores de telejornais tradicionais?

Palavras-chave

Tonalização. Condução. Mediação.

\section{Elizabeth Bastos Duarte | bebethb@terra.com.br}

Doutora em Lingüística e Semiótica pela Universidade de São Paulo - USP. Pós-doutora em Televisão pela École des Hautes Études en Sciences Sociales (França) e pela Université de Paris III Sorbonne Nouvelle (França). Professora permanente do Programa de PósGraduação da Universidade Federal de Santa Maria - UFSM.

Vanessa Curvello | nessacurvello@gmail.com Bolsista de apoio técnico - CNPq.

\section{Considerações introdutórias}

As investigações desenvolvidas pelo projeto

Produção televisual: entre formatos e tons vêm centrando sua atenção no exame do processo de tonalização do discurso televisual: nas suas relações com a temporalização e a espacialização; nas expectativas tonais dos diferentes subgêneros televisuais e nas estratégias de ruptura com essas expectativas; nas formas de expressão responsáveis pela manifestação do tom na produção televisiva. Como já se tentou mostrar em trabalhos anteriores, 0 tom normalmente se manifesta nos produtos televisuais de forma difusa, aproveitando-se, para marcar sua presença, da articulação dos diferentes níveis de linguagens, utilizados na expressão desse tipo de texto: harmonização de cores, formas e sons, jogo de câmeras e edição, registros de fala, figurinos, cenários, encenação, etc.

Desta vez, dando continuidade à pesquisa em desenvolvimento, inspirada e instigada por algumas afirmações de Jost (1999) e Barbero (2001), procurou-se focalizar a atenção nos casos em que 0 ator discursivo condutor de um 
programa televisual - apresentador, âncora, repórter, entrevistador - concentra em sua pessoa também uma função de mediação, encarregando-se, por delegação da enunciação, da proposição, modulação, gradação e manutenção do tom a ser conferido a um produto televisual.

Mas, para que se possa compreender essa função mediadora, é preciso, em primeiro lugar, não confundir os enunciadores de um produto televisual, responsáveis pelas deliberações concernentes ao tom, com a figura do ator discursivo que, no interior do texto do programa, por delegação dos enunciadores, pode assumir essa tarefa.

0 processo comunicativo televisual comporta diferentes níveis de sujeitos enunciadores: há uma instância enunciativa institucional, cujo enunciador é responsável institucionalmente pelas informações veiculadas; há uma instância de realização, representada pelos sujeitos que fazem parte da equipe de produção/realização de programa, cujo enunciador é coletivo; há uma instância discursiva, que pode conter enunciadores enunciados: são os atores discursivos, figuras de discurso que operam, no texto televisual, como apresentadores, animadores, âncoras, repórteres e/ou entrevistadores e que, no interior do programa, representam o papel de enunciadores; há ainda uma instância de representação simbólica do universo inscrito, pertencente aos sujeitos do mundo evocado, os telespectadores, que validam e caucionam os conteúdos propostos e os valores assumidos por um programa, respondendo ou não à combinatória tonal proposta.

Ora, as vozes das duas primeiras instâncias advêm da enunciação, estando ligadas tanto à realidade socioeconômica e às lógicas de realização, como à missão e à imagem que a instituição deseja construir de si frente ao público telespectador. E as emissoras falam, através de sua programação, dentre outras coisas, da forma como querem interagir com 0 telespectador em um dado programa, ou seja, do ponto de vista a partir do qual seu texto quer ser lido, dos valores colocados em pauta.

$$
\begin{aligned}
& \text { Aujourd'hui plus qu'hier, chaque début d'émis- } \\
& \text { sion annonce le ton qui va y dominer : il y aura } \\
& \text { des rires et des larmes, des « surprises », la } \\
& \text { révélation de secrets ou de la vérité. (JOST, } \\
& \text { 1999, p. 28). }
\end{aligned}
$$

$\mathrm{E}$, se esse tom é enunciado à partida, alguns subgêneros televisuais, entretanto, vão além: prevêem a figura do condutor do programa - apresentador, âncora, animador, repórter, enviado especial, entrevistador -, que é, muitas vezes, convocado, simultaneamente, para desempenhar também a função de mediador entre a instância de enunciação e os telespectadores virtuais ou reais.

A configuração do ator discursivo que acumula essas funções, condutor e mediador, essa é nossa hipótese, faz dele um instrumento muito 
eficaz na expressão do tom que se pretende conferir ao produto televisual. Daí o interesse em examinar: (1) alguns subgêneros e/ou formatos de programas em que esses atores discursivos, além de condutores, são também mediadores, ou seja, são responsáveis pela expressão, concentrada e centralizada, de uma combinatória tonal, compreendendo a proposição, modulação, gradação e manutenção dos tons que identificam o programa; (2) o subgênero telejornal, em particular, visto que os condutores desse tipo de programa normalmente não acumulam à condução a função de mediadores da combinatória tonal que identifica o programa. Trata-se de uma distinção sutil: eles agem e comportam-se, é verdade, de forma compatível com a combinatória tonal. Mas, tudo leva a crer que a emissora, no caso dos telejornais tradicionais, não abdica de seu papel de enunciadora, não lhes delega essa função, reservando-se o direito de controle e manutenção do tom, o que lhe permite, entre outras coisas, substituir esses apresentadores, quando necessário, sem prejuízo da manutenção do programa.

\section{Do processo de tonalização televisual}

A situação comunicativa televisual comporta, para além das âncoragens de tempo, espaço, aspecto e atores, um outro dispositivo sintático-semântico, aqui denominado de tonalização do discurso. Tal dispositivo diz respeito à conferência de um tom ou combinatória tonal ao discurso enunciado, ou seja, de um ponto de vista a partir do qual sua narrativa quer ser reconhecida. Embora 0 processo de tonalização seja uma decisão estratégica da instância da enunciação, ele atualiza a presença dos enunciatários na medida em que essa deliberação se refere aos traços indicadores do tipo e forma de interação que um produto televisual pretende manter com seus interlocutores.

Assim, o tom dirige-se, necessariamente, ao meio social. Sua escolha pressupõe um interlocutor virtual ou atual, o telespectador, que, na medida em que é capaz de perceber a proposição engajante de um programa, ou seja, de detectar o tom conferido a um produto televisual, torna-se cúmplice dos enunciadores, aderindo ao convite que lhe é feito pela instância de enunciação. Trata-se de um jogo demasiado astucioso para ser verdadeiramente informação ou mero entretenimento, cuja intenção estratégica é manter 0 telespectador cativo. Assim, "... une émission peut référer à la réalité ou à une ficcion, sur plusieurs tons" (JOST, 2005, p. 39); essa seleção, entretanto, não é arbitraria, mas intencional.

Ora, essa deliberação sobre 0 tom confere-lhe um caráter interpelativo: acertar o tom, ou melhor, sua expressão, implica que ele seja reconhecido e apreciado pelo telespectador. Se isso não ocorrer, todo o processo de tonalização fica comprometido - não obtém êxito. 
Como é previsível, a proposição de um tom orienta-se por um feixe de relações representadas pela tentativa de harmonização entre 0 subgênero do programa, o tema da emissão, o público a que se destina, e 0 tipo de interação que se pretende manter com 0 telespectador. A decisão sobre 0 tom oscila entre aspectos ligados à subjetividade e a objetividade dos enunciadores: as possíveis ambigüidades, contradições ou incoerências são o resultado desse vai-e-vem que implica a realização de um produto televisual. Mas a seleção de uma combinatória tonal não é nunca neutra ou inocente; procura sempre fazer jus ao conjunto de real que se quer dar a conhecer, a partir de um ponto de vista singular. Pressupõe movimentos de modulação, isto é, de passagem do tom principal aos a ele correlacionados; e de gradação, ou seja, de aumento ou diminuição de ênfase em determinado tom. Os tons combinamse entre si para dar corpo a um determinado programa televisual, o que obriga as marcas tonais responsáveis por sua expressão a se encaixarem no sofisticado mecanismo do produto, articulando-se harmonicamente com os outros componentes narrativos e discursivos, com os mecanismos expressivos, com os entornos e práticas sociais.

Como a produção televisual movimenta-se basicamente entre os dois objetivos fundamentais de informar e divertir - que ora são priorizados isoladamente, ora se combinam -, acredita-se que as demais categorias tonais se articulem em torno de uma categoria principal, disposição, cujos eixos opositivos estruturam-se em torno das tensões entre seus dois pólos extremos sobriedade e ludicidade (seriedade, gozação, espirituosidade, trivialidade).

Por outro lado, cada subgênero televisual atualiza, enquanto expectativa social ou prática de audiência, um tom ou uma combinatória tonal. Por exemplo, o tom principal, expectativa de um subgênero como o telejornal, é o de seriedade, pois ele confere efeitos de sentido de verdade, confiabilidade, credibilidade ao que está sendo noticiado. A esse tom principal, agregam-se tons complementares, tais como formalidade, neutralidade, contração, profundidade, etc..

No processo de realização de um subgênero televisual, cada formato manifesta sua escolha tonal, expressa por uma determinada combinatória de tons, que passam a identificar o programa, podendo ou não corresponder à expectativa tonal do gênero. Assim, 0 tom, como estrutura acionada pelo enunciador, compreende a relação entre o que já estava posto, sendo conhecido e preditível pelas normas do subgênero, e o que pode variar, dependendo do formato adotado. Isso faz com que cada emissão e/ou programa comporte elementos já dados e elementos novos; envia, obrigatoriamente, a combinatórias tonais pré-existentes, previstas pelo subgênero, mas reserva espaços para o novo, o surpreendente. A escolha entre essas opções tonais passa, então, a identificar um produto televisual enquanto formato. 
Com isso se quer dizer que todo subgênero televisual já tem como dado o tom que lhe seria adequado, mas que cada produto opcionalmente pode acessar novas combinatórias tonais que distingam seu formato do subgênero stricto sensu a que pertence. Trata-se de uma relação semântica estreita entre 0 que ditam as normas do subgênero, ponto de partida já conhecido pelo enunciador e 0 enunciatário, e o formato, que muitas vezes fratura ou rompe com seus tons de origem, substituindo-os, alterando-os, propondo novas combinatórias tonais que se tornem marcas registradas do programa, pois, mesmo que não sejam sempre absolutamente originais, atuam como signo de diferenciação, com forte potencial fidelizador do público telespectador.

Cabe ainda ressaltar que 0 tom normalmente se manifesta de forma disseminada e difusa. Assim, essa expressão, embora seja redundante na medida em que é reiterada através de sua articulação por diferentes substâncias e formas de expressão, apresenta-se de maneira dissipada, difusa, exigindo que se perscrute 0 texto em busca dos elementos que sustentam sua manifestação. Do ponto de vista discursivo, 0 processo de tonalização interfere na configuração dos atores, do tempo, do espaço, bem como na da própria organização narrativa. Em nível textual, ele se impõe como uma pretensão de conteúdo em busca de diferentes traços expressivos que o exteriorizem, ligandose a elementos como a harmonização de cores, formas e sons, o jogo de câmeras e edição, os registros de língua, o guarda-roupa, o cenário, a encenação. Existem, não obstante, produtos televisuais em que a expressão do tom concentra-se em uma figura discursiva.

\section{Actorialização do tom}

Le ton est une composante qui s'ancre principalement dans l'animateur, pour les émissions ressortissant aux mondes réel et ludique, ou dans les personnages, pour la fiction. (JOST, 2005, p. 40).

Alguns tipos de produtos televisuais, cuja estrutura conta com a presença de um condutor da emissão, fogem desse padrão disseminado, difuso e dissipado de expressão do tom, optando por uma manifestação mais concentrada e centralizada, representada por essa figura que convoca para si a responsabilidade da manifestação tonal. Como condutores apresentadores, animadores, repórteres, enviados especiais, entrevistadores - eles assumem papéis discursivos que se desdobram: narrador, animador-controle, apresentadoravaliador, guia-participante, intervindo em cena, gerenciando o tempo, realizando as transições entre os diferentes segmentos do programa, encarregando-se das debreagens e embreagens internas ao texto do programa (FONTANILLE, 2005, p.139). Muito deles atuam, ainda e simultaneamente, como mediadores entre as instâncias de enunciação e recepção, uma vez que centralizam e captalizam para si a tarefa de regulação dos valores e de manifestação do ponto de vista a partir do qual o programa quer ser lido, 
indicando a forma como o telespectador deve interagir com o programa. Como mediadores, esses atores operam por delegação: enunciam a enunciação do programa, passando a materializar tanto os valores investidos, como a combinatória tonal que deve identificar o programa, sendo os responsáveis, em ato, por sua proposição, gradação e manutenção.

Configurados por determinadas propriedades semânticas, narrativas e tonais, esses condutores-mediadores intervêm, modificando inevitavelmente a relação entre a instância da enunciação (informações institucionais) e a instância do enunciado (informações temáticas). Essa dupla participação se manifesta em sua atuação em cena, perpassando as modalidades de acolhimento e interação adotadas, as formas de ação e de controle da emissão: fazem, enfim, desses atores a encarnação da combinatória tonal que caracteriza o programa; eles a em-formam.

Uns poucos autores fazem referência a esse tipo de mediação, relacionando-a com a expressão do tom. Dentre eles, destacam-se algumas observações feitas por Martín-Barbero sobre esse tipo de intermediação do tom.

A televisão recorre a dois intermediários fundamentais: um personagem retirado do espetáculo popular, o animador ou apresentador, e um certo tom que fornece o clima exigido, coloquial. 0 apresentador-animador - presente nos noticiários, nos concursos, nos musicais, nos programas educativos e até nos "culturais", para reforçá-los -, mais do que um transmissor de informações, é na verdade um interlocu- tor, ou melhor, aquele que interpreta a família convertendo-a em seu interlocutor. Daí seu tom coloquial e a simulação de um diálogo que não se restringe a um arremedo do clima "familiar". (MARTÍN-BARBEIR0, 2001, p. 306)

A experiência de análise mostra, entretanto, que, diferentemente do que aponta Martín-Barbero, nem todo condutor é passível dessa acumulação de papéis - condutor e mediador. É necessário, para isso, que ele preencha determinadas condições que 0 tornem competente para representar os valores simbólicos e fiduciários de um produto e materializar a combinação tonal de uma emissão.

\section{Alguns exemplos}

Na história da televisão brasileira, há inúmeros exemplos do tipo de configuração discursiva a que se faz menção, ou seja, desse condutor/ mediador revestido de propriedades semânticas, narrativas e tonais que possibilitem essa acumulação de funções de diferentes níveis. Isso não quer dizer, evidentemente, que tais configurações discursivas sejam semelhantes entre si, ou que sigam um mesmo padrão. Ao contrário, é exatamente o que as distingue umas das outras que faz delas as principais responsáveis pela manifestação do tom do programa que presidem. Mas, como já se referiu, é necessário, para acumular condução e mediação, preencher determinadas condições.

A análise longamente realizada demonstrou, em primeiro lugar, que, para que um ator 
discursivo tenha êxito na acumulação dos papéis de condutor e mediador, existe a necessidade de um outro tipo de sincretismo: aquele que faz do ator discursivo um decalque dele próprio enquanto ator social, obrigando-o a protagonizar em cena uma caricatura de si próprio enquanto ator social. Para esse mise-en-scène, ele recorre a certos rituais - a insistência em determinados comportamentos, atitudes, gestos, jeitos e trejeitos; a utilização de certos bordões e figuras de linguagem; 0 uso de determinado estilo e figurino; o emprego de uma combinatória tonal que se cole a ele -, elementos que garantem a construção de uma identidade social que dota 0 ator discursivo de competência para operar simultaneamente como condutor e mediador da emissão, transformando-o na entidade principal de expressão da combinatória tonal que identifica o programa. Muitos desses condutoresmediadores são também os produtores de seus programas, e, no caso específico do Sílvio Santos, ele é também o proprietário da emissora - 0 Sistema Brasileiro de Televisão (SBT).

Esse é 0 caso, à guisa de ilustração, dos programas conduzidos/mediados por Abelardo Barbosa, o Chacrinha, Hebe Carmago, Sílvio Santos, Ana Maria Braga, Jô Soares, Regina Casé, Fernanda Young, Antônio Abujamra, Marília Gabriela. Possivelmente, nenhum desses programas sobreviva ao afastamento de seus condutores, vide Chacrinha. Esse, não obstante, não parece ser 0 caso dos telejornais.

\section{Caso específico: os telejornais}

As questões sobre as quais aqui se quer refletir são as seguintes: os apresentadores dos telejornais tradicionais ${ }^{1}$ acumulam essas duas funções - condutor do programa e mediador entre a instância da enunciação e os telespectadores -, capitalizando para si a responsabilidade de proposição, manutenção, modulação e gradação do tom dos telejornais? Ou o subgênero telejornal tem à partida uma combinatória tonal tão bem definida e necessária ao tipo de informação veiculada que não lhe convém a mediação centrada na figura do apresentador?

Desde o início da história da televisão no Brasil, o telejornal é um subgênero com presença e audiência garantida na programação televisiva. Importado do jornalismo radiofônico, a televisão dele se apropriou de forma descarada, adotando inicialmente no Brasil até mesmo o nome do noticiário mais famoso da época, o Repórter Esso. Tal apropriação, não obstante, trouxe, como é natural, implicações na construção de seu texto, que, se até então se caracterizava como um relato oral de notícias, utilizando como

Quando se fala de telejornais tradicionais, faz-se menção àqueles que respeitam as normas, ao longo dos últimos sessenta anos, cultivadas por esse subgênero. Lembra-se a esse respeito que é exatamente porque essas normas existem que os formatos que operam rupturas sobre elas surpreendem, entre outras coisas, pela mudança tonal. Esse é o caso do tom dramático empregado por alguns noticiários ou do tom apatifado e irreverente de Pânico na TV (Rede TV) e Custe o que custar - CQC (Band). 
principal recurso retórico a impostação de voz dos apresentadores, passou a se estruturar a partir da articulação entre imagens e sons, entre linguagens visuais e sonoras, sobredeterminadas pelos meios técnicos de produção, circulação e consumo dos produtos televisivos.

0 discurso do telejornal constrói-se tomando como referência o mundo real, exterior à mídia; trata-se de uma meta-realidade, cujo regime de crença proposto é a veridicção. Assim, o que funda os telejornais e lhes confere legitimidade é 0 relato objetivo do real, do mundo exterior. Uma boa notícia, dizem, deve ficar o mais próximo possível do acontecimento, mantendo em relação a ele fidelidade, neutralidade, objetividade. É aí que entra em questão a verdade, pois, a partir de um mesmo fato ou acontecimento, podem ser produzidos relatos bastante diferentes, todos verdadeiros, porque respeitam as fontes, mas todos diversos, porque operam seleções, focalizações e montagens diferentes. A televisão não reflete 0 real, ela 0 conforma. A transmissão direta, hoje em estágio de desenvolvimento sem precedentes, transcende distâncias e torna simultâneos os tempos do acontecimento e de sua exibição, permitindo a constituição de um público transnacional. Mas, embora pareça aderir totalmente ao acontecimento, permitindo-lhe ganhar existência, exatamente e tão-somente porque o mostra, ou seja, 0 transforma em acontecimento enunciado, ela não deixa, por isso mesmo, de ser apenas uma de suas configurações.
Dessa forma, para corresponder ao regime de crença proposto, a veridicção, os telejornais cercam-se de estratégias discursivas e mecanismos expressivos que garantam os efeitos de sentido de verdade, autenticidade, credibilidade de que carecem. Uma dessas estratégias, sem dúvida, é sua combinatória tonal. Do ponto de vista de sua expressão, os telejornais estruturam-se de forma a corresponder e sustentar seus traços tonais. Os telejornais operam com dois tipos de espaços: os internos, que são os espaços de estúdio, e os externos, que são próprios das ações do mundo, dos acontecimentos, conectados pelos dispositivos tecnológicos. Há toda uma tradiçãa de cuidado pelo cenário, pela escolha dos apresentadores ou âncoras, pela manutenção de posturas e comportamentos. Normalmente, os cenários dos telejornais colocam os apresentadores em um platô, isto é, em um estrado mais alto, sentados em uma bancada, tendo como fundo espécies de mapas de globo terrestre, ou telas e telões. Essa posição de superioridade já assinala de antemão quem, nesse contexto, detém a informação e, conseqüentemente, 0 poder. 0 fundo do cenário aponta para o domínio que a emissora e 0 programa detêm sobre a informação de acontecimentos em nível planetário. Mais ainda, completando esse cenário, muitas vezes, ao redor desse platô central, mas em plano mais abaixo, há uma série de mesas de trabalho com pessoas, todas em movimento, operando computadores, algumas até mesmo caminhando apressadamente 
de um lado para o outro. Essa complementação do cenário com a redação em plano mais baixo garante os efeitos de atualidade do noticiário. É como se a notícia estivesse chegando quentinha, pronta para entrar no ar, mesmo quando na verdade se tratam das "requentadas". Além disso, ao mostrar os seus bastidores, o em-sefazendo da notícia, e, com isso, suas condições tecnológicas, a emissora promove, para além do programa, a si própria. 0 grande número de pessoas que trabalham de certa maneira aponta para consideração e respeito da emissora pelo telespectador: todo aquele contingente está a serviço do telespectador para lhe oferecer a notícia de última hora.

Do ponto de vista tonal, os telejornais, em seus formatos mais tradicionais, centram suas estratégias em torno do tom seriedade, aliado a termos das categorias tratamento: formalidade vs. informalidade; ritmo: regularidade vs. irregularidade; posição: neutralidade, distanciamento vs. proximidade; espessura: superficialidade vs. profundidade, tanto no que concerne à construção, como ao esquentamento de matérias já apresentadas em jornais anteriores. Assim, ao tom de seriedade alinham-se outros, comoformalidade, contração, neutralidade,

\section{distanciamento, profundidade, regularidade,} etc., que vêm reforçar a seriedade necessária aos efeitos de verdade e credibilidade ${ }^{2}$.

Ora, nesse contexto, qual é a função dos apresentadores e até que ponto eles desempenham a função de mediadores? As emissoras investem nos apresentadores pelo tom de seriedade que esses possam conferir ao programa, o que é avesso a expressões de personalidade e subjetividade que distinguiriam 0 apresentador. Daí a impessoalidade, a neutralidade; muitas vezes, a apresentação é feita em dupla, o que, em princípio, implica a divisão de funções e do poder catalisador do apresentador, desviando a atenção dos telespectadores. A seriedade, no caso dos apresentadores, tem como formas de expressão a aparência física, a postura corporal, o penteado, 0 vestuário, o comportamento contido, a voz pausada, o uso impecável da linguagem verbal, etc., mas ela é extensiva, via de regra, a todos que ocupam a função de apresentadores de telejornal. Por outro lado, como já se referiu, há, além disso, toda uma outra gama de mecanismos expressivos que corroboram a manutenção desses tons de seriedade, formalidade, neutralidade, colados ao que é dito ou mostrado.

Pode-se sempre romper com as expectativas tonais do subgênero: em 2003, o SBT lançou um telejornal que se chamava SBT Manhã, recheado de notícias requentadas e apresentado por Cíntia Benini, jornalista e atriz, e Analice Nicolau, modelo e atriz, participantes da Casa dos artistas. As duas integrantes do reality show não se restringiam à bancada; caminhavam pelo platô de mini-saia, exibindo suas pernocas, e fazendo comentários tolos. Foi, sem dúvida, uma forma de apatifar com o tom de seriedade tradicionalmente conferido aos telejornais, contra o que a RedeTv reagiu no humorístico Pânico na Tv, com uma paródia, apresentada em 03/07/03 em que as protagonistas, Sabrina Sato e Tânia Oliveira, de microssaias, cruzavam as pernas, de forma exagerada, mostrando as calcinhas. Mas, convenhamos, esse tipo de ruptura não é comum. Estamos acostumados à mesmice que responde às expectativas do subgênero. 
Esses mecanismos dão-se a ver na seqüência das emissões, não só pela repetição ancorada na reiteração dos cenários, do número de blocos, da forma de estruturação desses blocos, dos bordões de abertura e de passagem de um bloco a outro, e de fechamento, etc. -, como pela presença e comportamento reiterado dos apresentadores, dia após dia, ano após ano.

A Globo, por exemplo, que adota esses formatos tradicionais, vem apostando, ao longo dos anos, na velha fórmula de contratar casais de apresentadores. Um exemplo típico do engessamento do formato global é a dupla de apresentadores Willian Bonner e Fátima Bernardes, que, de tão impecáveis, comedidos, formais, bem comportados, só fazem confirmar que uma das grandes estratégias de sustentação dessa credibilidade é a conferência de um tom de seriedade. Mas, esses dois jornalistas, também um casal fora das telas, que apresentam desde 1998, de segunda a sexta-feira, o Jornal Nacional, telejornal diário da Rede Globo de Televisão (RGT) com maior audiência no país (exibido aproximadamente às 20h15), são muitas vezes substituídos por outros apresentadores da emissora, que se revezam na bancada aos sábados, feriados e durante as férias do casal, sem que os telespectadores reclamem. Ao contrário, isso passa batido, muitas vezes sem que se perceba essa substituição.

E, assim como no caso do casal de apresentadores, em outros telejornais como os do SBT, Band, Globo News, os apresentadores se revezam, fazem incursões de uma emissora a outra, a maioria deles, é verdade, treinada pela RGT, sem que os telespectadores reclamem e, menos ainda, que o telejornal tenha que sair do ar. É assim com Ana Paula Padrão (SBT), Carlos Nascimento (SBT), Hermano Henning (SBT) e outros.

Todos esses exemplos levam à confirmação da hipótese de que, no caso dos apresentadores de telejornais tradicionais, as emissoras não delegam somente a eles a função de mediação tonal, até porque isso não lhes interessa, visto que o programa deve permanecer no ar, aconteça o que acontecer. Elas permitem, isto sim, quadros como os de Paulo Francis, Arnaldo Jabor, Boris Casoy e outros comentaristas, que, se imprimem o tom ao quadro que apresentam, esse tom não é extensivo ao telejornal como um todo.

\section{6 À guisa de conclusão}

Ce ton caractérise souvent l'animateur et constitue une des dimensions de la marque qu'il incarne, au point que des genres aux dispositifs différents finissent par se ressembler (JOST, 1999, p. 28).

Assim, trata-se de uma questão de ênfase: para que esse sincretismo condutor/mediador ocorra, é necessário que 0 ator envolvido nesse tipo de processo comunicativo acumule papéis sociais e discursivos, que possibilitem uma identificação entre 0 ator social e 0 ator discursivo, permitindo a identificação do ator social com 
o próprio programa, e do ator discursivo com os valores simbólicos por ele representados enquanto ator social.

Aliás, são por determinadas características, pela imagem construída para si enquanto ator social - mordacidade, ironia, argúcia, descontração

- que esses sujeitos normalmente são escolhidos para comandar um programa, no qual devem, enquanto atores discursivos, representar de forma caricaturesca a si mesmos enquanto atores sociais. Mas, essa encenação contradiz tudo o que se espera do apresentador de um telejornal tradicional.

A função de mediador implica diferença, pois 0 ator discursivo que assume essa função passa a ser identificado com o programa, colocando em destaque os valores simbólicos e os traços tonais que se pretendem veicular.

Assim, atores discursivos - como os que operam como mediadores de alguns talk-shows, magazines, revistas eletrônicas, entrevistas, reportagens, etc. - podem assumir essas configurações discursivas distintas, sendo, em conseqüência, portadores da expressão tonal do programa.

Pode-se dizer então que há:

(1) os condutores utilizados como reiteração da combinatória tonal identificadora de um programa televisual. Nesse caso, a ênfase tonal recai sobre o programa como um todo. Naturalmente o condutor a reforça, porque seu papel actorial é compatível com ela, impregnando as múltiplas funções por ele desempenhadas: controle, avaliação, guia. Embora esse ator possa ser confundido com o programa, ele não é 0 programa. Tanto isso é verdade que, enquanto condutor, pode ser substituído, sem que a emissão ou programa perca a tonalidade que lhe é característica. Esse é o caso da maior parte dos apresentadores de telejornais;

(2) os condutores/mediadores, que capitalizam para si a expressão da combinatória tonal de um programa, protagonizando-a, encarnando-a. Nesse caso, o seu afastamento decreta a morte do programa.

\section{Referências bibliográficas}

CHARAUDEAU, Patrick. Le discours d'information médiatique: la construction du miroir social. Paris: Nathan, 1997.

DICIONÁRIO da TV Globo. Programas de dramaturgia e entretenimento. Rio de Janeiro: Zahar Ed., 2003. (Projeto Memória das Organizações Globo)

DUARTE. Elizabeth Bastos Duarte. Televisão: ensaios metodológicos. Porto Alegre: Sulina, 2004. (vol.1). ; CASTR0, Maria Lília Dias de (orgs.). Televisão: entre o mercado e a academia. Porto Alegre: Sulina, 2006. (Coleção Estudos sobre 0 audiovisual, vol. 4).

FECHINE, Yvana. A instauração da temporalidade no telejornal. In: Caderno da Compós XI Encontro da Associação Nacional dos programas de Pós-Graduação em Comunicação. Rio de Janeiro: Eco/UFRJ, p.35-52, 2002.

FONTANILLE, Jacques. Significação e visualidade: exercícios práticos. Porto Alegre: Sulina, 2005. 
GREIMAS, A.A propósito do jogo. Verso e Reverso, São Leopoldo, Unisinos, ano VII, n. 27, p. 119-123, jul./dez. 1999.

GREIMAS, A. J.; COURTÈS, J. Dicionário de semiótica. São Paulo: Cultrix, 1989.

JOST, François. Comprendre la télévision. Paris: Armand Colin, 2005.

JOST, François. Introduction à l'analyse de la télévision. Paris: Ellipses, 1999.

MARTÍN-BARBEIRO, Jesus. Dos meios às mediações: comunicação, cultura e hegemonia. Rio de Janeiro: UFRJ, 2001. 
News on TV: Who gives the tone?

\section{Abstract}

This paper intends, continuing the investigations developed on the process of tonalization of television products, to examine carefully the role developed in certain television programs by the discursive actor who conducts the program. Presenters, entertainers, anchors, interviewers many times concentrate on themselves, besides the task of conducting the broadcast itself, the role of mediators between the instance of enunciation and the enunciataries of the television text, responsible for proposing, modulating, gradating and maintaining the tone of the broadcast television, with particular attention to the presenters of traditional news programs.

\section{Keywords}

Tonalization. Conduction. Mediation.

\section{Noticieros en televisión: ¿quién les da el tono?}

\section{Resumen}

Este trabajo se propone, dando continuidad a las investigaciones sobre el proceso de tonalización de productos televisivos, a examinar cuidadosamente el papel desempeñado en algunos programas de televisión por el actor discursivo conductor del programa. Presentadores, animadores, entrevistadores parecen concentrar en si mismo, más que la tarea de la conducción de la emisión, la función de mediación entre la enunciación de los textos televisivos y le enunciatario, siendo responsable por la proposición, modulación, gradación y mantenimiento del tono de la emisión, con especial atención a los presentadores de noticieros de televisión.

\section{Palabras clave}

Tonalización. Conducción. Mediación. 


\section{Expediente}

A revista E-Compós é a publicação científica em formato eletrônico da Associação Nacional dos Programas de Pós-Graduação em Comunicação (Compós). Lançada em 2004, tem como principal finalidade difundir a produção acadêmica de pesquisadores da área de Comunicação, inseridos em instituições do Brasil e do exterior.
E-COMPÓS I www.e-compos.org.br I E-ISSN 1808-2599

Revista da Associação Nacional dos Programas de Pós-Graduação em Comunicação. Brasília, v.11, n.2, maio/ago. 2008

A identificação das edições, a partir de 2008 passa a ser volume anual com três números.

\section{CONSELHO EDITORIAL}

\section{Afonso Albuquerque}

Universidade Federal Fluminense, Brasil

Alberto Carlos Augusto Klein

Universidade Estadual de Londrina, Brasi

Alex Fernando Teixeira Primo

Universidade Federal do Rio Grande do Sul, Brasi

Alfredo Vizeu

Universidade Federal de Pernambuco, Brasil

Ana Carolina Damboriarena Escosteguy

Pontifícia Universidade Católica do Rio Grande do Sul, Brasil

Ana Silvia Lopes Davi Médola

Universidade Estadual Paulista, Brasil

André Luiz Martins Lemos

Universidade Federal da Bahia, Brasil

Ângela Freire Prysthon

Universidade Federal de Pernambuco, Brasil

Antônio Fausto Neto

Universidade do Vale do Rio dos Sinos, Brasil

Antonio Carlos Hohlfeldt

Pontifícia Universidade Católica do Rio Grande do Sul, Brasil

Arlindo Ribeiro Machado

Universidade de São Paulo, Brasil

César Geraldo Guimarães

Universidade Federal de Minas Gerais, Brasi

Cristiane Freitas Gutfreind

Pontifícia Universidade Católica do Rio Grande do Sul, Brasil

Denilson Lopes

Universidade Federal do Rio de Janeiro, Brasil

Eduardo Peñuela Cañizal

Universidade Paulista, Brasil

Erick Felinto de Oliveira

Universidade do Estado do Rio de Janeiro, Brasil

Francisco Menezes Martins

Universidade Tuiuti do Paraná, Brasil

Gelson Santana

Universidade Anhembi/Morumbi, Brasil

Hector Ospina

Universidad de Manizales, Colômbia

leda Tucherman

Universidade Federal do Rio de Janeiro, Brasil

Itania Maria Mota Gomes

Universidade Federal da Bahia, Brasil

Janice Caiafa

Universidade Federal do Rio de Janeiro, Brasil

Jeder Silveira Janotti Junior

Universidade Federal da Bahia, Brasil
John DH Downing

University of Texas at Austin, Estados Unidos

José Luiz Aidar Prado

Pontifícia Universidade Católica de São Paulo, Brasil

José Luiz Warren Jardim Gomes Braga

Universidade do Vale do Rio dos Sinos, Brasi

Juremir Machado da Silva

Pontifícia Universidade Católica do Rio Grande do Sul, Brasil

Lorraine Leu

University of Bristol, Grã-Bretanha

Luiz Claudio Martino

Universidade de Brasília, Brasil

Maria Immacolata Vassallo de Lopes

Universidade de São Paulo, Brasil

Maria Lucia Santaella

Pontifícia Universidade Católica de São Paulo, Brasil

Mauro Pereira Porto

Tulane University, Estados Unidos

Muniz Sodre de Araujo Cabral

Universidade Federal do Rio de Janeiro, Brasil

Nilda Aparecida Jacks

Universidade Federal do Rio Grande do Sul, Brasil

Paulo Roberto Gibaldi Vaz

Universidade Federal do Rio de Janeiro, Brasil

Renato Cordeiro Gomes

Pontifícia Universidade Católica do Rio de Janeiro, Brasil

Ronaldo George Helal

Universidade do Estado do Rio de Janeiro, Brasil

Rosana de Lima Soares

Universidade de São Paulo, Brasil

Rossana Reguillo

Instituto Tecnológico y de Estudios Superiores do Occidente, México

Rousiley Celi Moreira Maia

Universidade Federal de Minas Gerais, Brasil

Sebastião Carlos de Morais Squirra

Universidade Metodista de São Paulo, Brasil

Simone Maria Andrade Pereira de Sá

Universidade Federal Fluminense, Brasil

Suzete Venturelli

Universidade de Brasília, Brasil

Valério Cruz Brittos

Universidade do Vale do Rio dos Sinos, Brasil

Veneza Mayora Ronsini

Universidade Federal de Santa Maria, Brasil

Vera Regina Veiga França

Universidade Federal de Minas Gerais, Brasil

\section{COMISSÃO EDITORIAL}

Ana Gruszynski I Universidade Federal do Rio Grande do Sul, Brasil João Freire Filho I Universidade Federal do Rio de Janeiro, Brasil Rose Melo Rocha I Escola Superior de Propaganda e Marketing, Brasil

\section{CONSULTORES AD HOC}

Aníbal Bragança I Universidade Federal Fluminense, Brasi Gisela Castro I Escola Superior de Propaganda e Marketing, Brasil

Gislene Silva I Universidade Federal de Santa Catarina, Brasil

Maria Helena Weber I Universidade Federal do Rio Grande do Sul, Brasil

Rosana de Lima Soares I Universidade de São Paulo, Brasil

Tania Hoff I Escola Superior de Propaganda e Marketing, Brasil

REVISÃO DE TEXTO E TRADUÇÃo I Everton Cardoso

ASSISTÊNCIA EDITORIAL E EDITORAÇÃO ELETRÔNICA I Raquel Castedo
COMPÓS I www.compos.org.br

Associação Nacional dos Programas de Pós-Graduação em Comunicação

Presidente

Erick Felinto de Oliveira

Universidade do Estado do Rio de Janeiro, Brasil erickfelinto@uol.com.br

Vice-presidente

Ana Silvia Lopes Davi Médola

Universidade Estadual Paulista, Brasil

asilvia@faac.unesp.br

Secretária-Geral

Denize Correa Araújo

Universidade Tuiuti do Paraná, Brasil

denizearaujo@hotmail.com 